\title{
Different subcellular localization and trafficking properties of KNOX class 1 homeodomain proteins from rice
}

\author{
Suzanne J.H. Kuijt ${ }^{1}$, Gerda E.M. Lamers, Saskia Rueb, Enrico Scarpella ${ }^{2}$, \\ Pieter B.F. Ouwerkerk, Herman P. Spaink and Annemarie H. Meijer* \\ Institute of Biology, Leiden University, Wassenaarseweg 64, 2333 AL, Leiden, the Netherlands (* author for \\ correspondence; e-mail meijer@rulbim.leidenuniv.nl)
}

Received 7 April 2004; accepted in revised form 8 August 2004

Key words: homeodomain protein, knox gene, localization, Oryza sativa, plant hormones, trafficking

\begin{abstract}
Genes of the KN1-like homeobox (KNOX) class 1 encode transcription factors involved in shoot apical meristem development and maintenance. We studied the subcellular localization of Green Fluorescent Protein-tagged rice KNOX proteins (Oskn1-3) after particle bombardment of onion and rice cells and after transformation of Arabidopsis and rice with constitutive and inducible expression constructs. In all test systems, the three rice KNOX proteins showed nuclear and cytoplasmic localization patterns. However, Oskn1 additionally showed in some cells a distribution over punctae moving randomly in the cytosol. Use of an inducible expression system indicated a nuclear presence of Oskn1 in cells of the shoot apical meristem and post-transcriptional down-regulation in early leaf primordia. Arabidopsis and rice test systems were used to study effects of plant hormones and auxin transport inhibition on KNOX protein localization. Application of $\mathrm{GA}_{3}$ or 1-NAA shifted protein localization completely to the cytoplasm and resulted in loss of the punctae formed by Oskn1. Conversely, NPA application induced a complete nuclear localization of the KNOX proteins. To study intercellular movement of the KNOX proteins we set up a novel co-bombardment assay in which trafficking of untagged KNOX proteins was visualized through the co-trafficking of green fluorescent or blue fluorescent marker proteins. In multiple independent experiments Oskn1 trafficked more extensively to neighboring cells than Oskn2 and Oskn3. Differences in the localization and trafficking properties of Oskn1, Oskn2 and Oskn3 correlate with differences in mRNA localization patterns and functional differences between the rice KNOX genes and their putative orthologues from other species.
\end{abstract}

Abbreviations: 1-NAA, naphtalene-1-acetic acid; 2,4-D, 2,4-dichlorophenoxy acidic acid; BAP, benzylaminopurine; BFP, blue fluorescent protein; DAPI, 4,6-diamidino-2-phenylindole; ER, endoplasmic reticulum; GA, gibberellic acid; GFP, green fluorescent protein; IAA, indole-3-acetic acid; KN1, KNOTTED1; KNAT, Arabidopsis thaliana; KNOX, Knotted-1 like homeobox; NLS, nuclear localization signal; NPA, 1-N-naphthylphthalamic acid; OSH, Oryza sativa homeobox; OSKN, Oryza sativa KNOX; SAM, shoot apical meristem; SEL, size exclusion limit; NCAPP1, non-cell-autonomous pathway protein1; SHR, SHORT-ROOT; STM, SHOOTMERISTEMLESS; WUS, WUSCHEL

\footnotetext{
${ }^{1}$ Present address: Max-Planck-Institut für Züchtungsforschung, Carl-von-Linné Weg 10, 50829 Köln, Germany.

${ }^{2}$ Present address: Department of Biological Sciences, University of Alberta, CW405 Biological Sciences Building, Edmonton AB, Canada T6G 2E9.
}

\section{Introduction}

Slowly dividing pluripotent stem cells from the core of the shoot apical meristem (SAM) in plants. 
Their derivatives in the peripheral zone of the SAM become specified to form the founder cells of organ primordia. The complex process of SAM organization requires the interaction of a large number of transcription factors and other regulatory proteins to fine-tune activities of cell division, specification and differentiation. Transcription factors involved in SAM organization include the KNOX class-1 homeodomain proteins, which have been named after the maize protein KNOTTED1 (KN1) and are involved in maintenance of the undifferentiated state of stem cells (Hake et al., 1995; Endrizzi et al., 1996; Brand et al., 2002). It has been proposed that the process of SAM maintenance depends on inhibition of gibberellin (GA) biosynthesis through down-regulation of GA20-oxidase by KNOX proteins (Kusaba et al., 1998; Sakamoto et al., 2001; Hay et al., 2002, 2004). In addition, interactions between KNOX genes and other plant hormones appear to be involved (Hamant et al., 2002; Scanlon, 2003; Hay et al., 2004).

Plasmodesmata facilitate intercellular communication in plants, which is essential for proper development of tissues and organs and for the coordination of stress responses (Clark, 2001b). With certain restrictions, signaling molecules, ranging from low molecular weight plant hormones to relatively large macromolecules like the KNOX proteins, can pass the cell wall through plasmodesmata (Sessions et al., 2000; Hake, 2001). These intercellular communication channels can transport molecules up to a certain size, defined as the size exclusion limit (SEL). The SEL varies between plant species, plant organs and different tissues within organs and is developmentally regulated (Gisel et al., 1999; Pickard and Beachy, 1999; Ormenese et al., 2000; Kim et al., 2002a). Specific proteins have the capacity to dilate plasmodesmata, enabling large proteins, ribonucleoprotein complexes and viral particles to pass through (Lucas, 1999). Dilation of plasmodesmata is an active process triggered by the protein that is to be transported, and is reversed after its passage (Kragler et al., 1998). The plasmodesmal transport pathway appears to involve specific interactions between the non-cell-autonomous proteins and the plasmodesma, but the complexity of plasmodesmal regulation is still far from understood. Kragler et al. (2000) identified a peptide antagonist, related to a sequence present in the $\mathrm{N}$-terminal region of
KN1, which could block the SEL increase associated with trafficking of KN1 and block completely the trafficking of its mRNA (Kragler et al., 2000). A potential regulatory component of the plasmodesmal machinery in tobacco, Non-Cell-Autonomous pathway protein 1 (NCAPP1), has recently been isolated. NCAPP1 is an ER-anchored cytoplasmic protein that localizes to the cell periphery close to the plasmodesmata. Mutants of NCAPP1 are blocked in intercellular trafficking of a viral movement protein (Jackson and Kim, 2003; Lee et al., 2003). Since trafficking of KN1 was not affected in the mutants, plasmodesmal regulatory proteins probably control protein trafficking in a specific manner.

It is likely that trafficking of $\mathrm{KN} 1$ plays a functional role in SAM development. KN1 mRNA is present in the central zone of the SAM, except for the outer cell layer (L1). The protein, however, was also observed in the L1 layer suggesting that it might be able to traffic from the inner cell layer (L2) to the L1 layer (Jackson et al., 1994; Jackson, 2002). The first direct evidence for protein trafficking was obtained from micro-injection experiments in tobacco leaves (Lucas et al., 1995). In this study, an alanine scanning mutation in the N-terminal part of the homeodomain led to a complete loss of the trafficking ability of KN1 protein. Subsequently, studies in Arabidopsis leaves with a fusion construct of $\mathrm{KN} 1$ and green fluorescent protein (GFP) provided direct evidence that KN1 can traffic from internal tissues to the epidermis (Kim et al., 2002b). Significantly, the trafficking ability of KNOX proteins is required for complementation of the stm-11 mutation in Arabidopsis by KN1. Expression in the L1 of a cell-autonomous fusion of KN1 to GUS did not complement the stm-11 mutant, which strongly suggested that trafficking of KNOX proteins in the SAM is functionally significant and possibly essential for its normal function in SAM initiation and maintenance (Kim et al., 2003).

In addition to $\mathrm{KN} 1$, several other regulatory proteins involved in SAM development display intercellular trafficking. In Arabidopsis, maintenance of stem cells in the SAM needs the combined action of WUSCHEL (WUS) and SHOOTMERISTEMLESS (STM) proteins, which are expressed in separate domains (reviewed in Baurle and Laux, 2003). Stem cell identity is specified by a signal emanating from the subjacent $W U S$-expressing 
organizing center (Schoof et al., 2000) and feedback loops between WUS and STM are dependent on the non-cell autonomous action of STM (Clark, 2001a; Fernandez et al., 2001). The transcription factors Deficiens and Leafy, involved in flower development, also display non-cell autonomous functions (Perbal et al., 1996; Sessions et al., 2000). Finally, trafficking of the transcription factor SHORTROOT (SHR) from the stele to the endodermis is essential for the radial patterning of Arabidopsis roots (Nakajima et al., 2001).

In addition to the functional significance of trafficking of KNOX proteins, control of their subcellular localization might act as a fine-tuning mechanism for their proper functioning (Vandromme et al., 1996). For certain animal homeodomain proteins, regulation of their subcellular localization represents an important control mechanism for their transcriptional activity. For example, the homeodomain protein Engrailed, involved in midbrain/hindbrain patterning of vertebrates, shuttles between nuclear and non-nuclear compartments owing to the presence of specific import and export sequences (Maizel et al., 1999).

In this study we investigated the subcellular localization patterns and intercellular trafficking properties of three KNOX class 1 homeodomain proteins from rice, named Oskn1 (OSH1), Oskn2 (OSH71) and Oskn3 (OSH15) (Sentoku et al., 1999; Postma-Haarsma et al., 2002). The subcellular localization patterns showed variation between the individual KNOX proteins and between tissues. Furthermore, the subcellular localization of the KNOX proteins could be influenced by plant hormones. To study intercellular trafficking of the KNOX proteins we developed an assay in which the movement of KNOX proteins to neighboring cells could be visualized by means of the co-trafficking of a fluorescent marker protein. Application of this assay revealed differences between the rice KNOX proteins in the extent of intercellular trafficking.

\section{Materials and methods}

\section{Vector constructions}

Fusions of Oskn1, Oskn2 and Oskn3 cDNA clones (Postma-Haarsma et al., 1999) to sGFP(S65T) were made in $\mathrm{pTH} 2^{\mathrm{BN}}$ (for C-terminal fusions to GFP) and $\mathrm{pTH} 2^{\mathrm{SN}}$ (for $\mathrm{N}$-terminal fusions to GFP), both derived from the pTH2 vector (Chiu et al., 1996). $\mathrm{pTH} 2^{\mathrm{BN}}$ was created by introducing a linker (GTACAAGATCTCCGAATTCCTCGAGGGACTAGTGC) into the BsrGI and NotI sites of $\mathrm{pTH} 2^{\Delta \mathrm{eco}}$. $\mathrm{pTH} 2^{\Delta \mathrm{Eco}}$ was derived from $\mathrm{pTH} 2$ by introducing a linker (AATTGGGTACCC) into the EcoRI site, resulting in loss of the EcoRI site and creation of a KpnI-site. pTH2 $2^{\mathrm{SN}}$ was created by introducing a linker (TCGACGAATTCACTAGTAC) into the SalI and NcoI sites of pTH $2^{\Delta \mathrm{Eco}}$. Next, Oskn1 was cloned into $\mathrm{pTH} 2^{\mathrm{BN}}$ using BglII and XhoI. Oskn2 and Oskn3 were cloned into pTH $2^{\mathrm{BN}}$ using EcoRI and XhoI. All three KNOX genes were cloned into $\mathrm{pTH} 2^{\mathrm{SN}}$ using SalI and NcoI. All other constructs used in transient bombardment assays were also pTH2derived. The GFP-nuclear localization signal (NLS) fusion is the pTH4 vector as described by Chiu et al. (1996). The GFP with ER-targeting signal is the mGFP5ER as published by Haseloff et al. (1997). To construct a GFP:Oshox1 fusion, the Oshox1 cDNA clone (Genbank Accession X96681) was excised from pUC28 using XbaI and NotI and cloned in the corresponding sites of pTH2 . The antisense Oskn1 construct was made in expression vector pMOG181 (MOGEN International, Leiden, the Netherlands), which contains a CaMV 35S promoter with double enhancer and a nos terminator.

For constitutive expression of KNAT2, a CaMV 35S-driven expression cassette was constructed in a binary vector. For this, the EcoRI site of pC1300intB (Genbank Accession AF294977) was removed by inserting the same linker as was used for $\mathrm{pTH} 2^{\Delta \mathrm{Eco}}$, creating pC1300intB ${ }^{\Delta \mathrm{Eco}}$. Subsequently, the CaMV 35S-promoter and nos-terminator of $\mathrm{pTH} 2^{\mathrm{SN}}$ were simultaneously inserted as HindIII/EcoRI and EcoRI/KpnI fragments into the HindIII/KpnI sites of $\mathrm{pC} 1300$ intB $^{\Delta \mathrm{Eco}}$, creating the binary vector pC1300intB-35SnosEX (AY560325). To complete the 35S-KNAT2 construct, an EST clone of KNAT2 (Genbank Accession U14175, clone 240N22 from the Arabidopsis Biological Resource Center and DNA Stock Center, Ohio State University, Columbus, $\mathrm{OH}$ 43210-1002) was excised using EcoRI and $\mathrm{XbaI}$ and cloned into pC1300intB-35SnosEX digested with EcoRI and SpeI. For stable transformation of plants with gene constructs for 
constitutive expression of GFP-tagged KNOX proteins, the expression cassettes prepared in the pTH2-constructs, containing the CaMV 35S-promoter, the KNOX:GFP fusion and the nos-terminator, were cloned between the HindIII and KpnI sites of pC1300intB (Genbank Accession AF294977). For glucocorticoid-inducible expression we used the pINDEX-system (Ouwerkerk et al., 2001). From $\mathrm{pTH} 2^{\mathrm{BN}}$ a cassette containing GFP:Oskn1 or GFP:Oskn2 was excised using SpeI and SalI and cloned into the SpeI and XhoI sites of pINDEX1 (Genbank Accession AF294979). As a control, GFP was excised from pTH2 using XbaI and PstI and cloned into the SpeI and SspBI sites of pINDEX2 (Genbank Accession AF294980). The binary vectors were transferred from Escherischia coli strain $\mathrm{DH} 5 \alpha$ to Agrobacterium tumefaciens strain LBA 4404 (for rice transformation) or LBA 1115 (for Arabidopsis transformation) via tri-parental mating. Plant phenotypes were observed and photographed using a Leica MZ12 stereomicroscope equiped with a Sony3CCD camera (DKC 5000).

\section{Transient bombardment assays}

Particle bombardment assays were performed on the abaxial side of adaxial epidermal peels from onion bulb scales and on the adaxial epidermis of rice leaf blade. DNA was precipitated onto a $1: 1$ mixture of 1.0 and $1.6 \mu \mathrm{m}$ diameter gold particles and bombarded on the specimens using a helium gun (BioRad Biolistics Particle Delivery System) and rupture discs of $1550 \mathrm{psi}$ (for onion) and $2200 \mathrm{psi}$ (for rice leaf). Bombarded tissue were incubated on MS-medium at $28^{\circ} \mathrm{C}$ for $24-48 \mathrm{~h}$. Rice suspension cells of Indica cultivar IR52 (grown in liquid LS [Linsmaier-Skoog] medium with $4.0 \mathrm{mg} \mathrm{l}^{-1} 2,4-\mathrm{D}$, shaking at $120 \mathrm{rpm}$ at $28{ }^{\circ} \mathrm{C}$ in the dark) were collected on a filter and bombarded using a helium particle inflow gun (home-made) with a mixture of tungsten particles (kindly supplied by Pioneer HiBred) and DNA. After bombardment the filters were placed on solid LS-medium containing $4.0 \mathrm{mg}^{-1}$ 2,4-D and incubated for 2 days at $28{ }^{\circ} \mathrm{C}$ in the dark before observations.

Observations were made with a Leica MZ FL111 stereomicroscope equipped with a mercury lamp and GFP filter set (480/40 nm excitation and $525 / 50 \mathrm{~nm}$ emission). Subcellular localization was studied using a BioRad $600 /$ Zeiss Axiovert confocal laser scanning microscope with a Princeton Gamma MicroMax CCD camera and image handling system or using a Leica TCS /SP DM IRBE confocal laser scanning microscope equipped with $\mathrm{He} / \mathrm{Ne}, \mathrm{Ar}$ and $\mathrm{Kr}$ lasers and a Coherent Mira 900F tunable 2-photon laser. Images were processed using Image $\mathbf{J}$, Confocal Assistant and Corel Photopaint software.

\section{Plant transformation and growth conditions}

Arabidopsis thaliana ecotype Colombia-0 was transformed by floral dip (Clough and Bent, 1998). Arabidopsis seeds were surface sterilized, sown on half strength MS (Murashige-Skoog)-medium, containing $20 \mathrm{mg} \mathrm{l}^{-1}$ hygromycin, $100 \mathrm{mg} \mathrm{l}^{-1}$ nystatin and $100 \mathrm{mg} \mathrm{l}^{-1}$ timentin, incubated in the dark at $4{ }^{\circ} \mathrm{C}$ for $72 \mathrm{~h}$ before germination at $21^{\circ} \mathrm{C}$ under a 16-h photoperiod. Plants of 3-4 weeks old were transferred to soil and grown at $21^{\circ} \mathrm{C}$ under a 16h photoperiod and $60 \%$ relative humidity. Arabidopsis roots for observation in CLSM were harvested from tissue culture only. For hormone studies, seedlings were transferred 4 days after germination to half strength MS medium con-

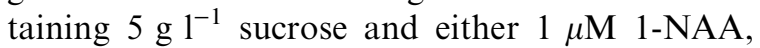
$1 \mu \mathrm{M}$ NPA, $10 \mu \mathrm{M}$ BAP or $10 \mu \mathrm{M} \mathrm{GA}_{3}$ and grown for 2 days at $21{ }^{\circ} \mathrm{C}$ under a 16 -h photoperiod prior to observations.

Transformation of Oryza sativa Japonica cultivar Taipei309 was performed as previously described by Scarpella et al. (2000), except that Agrobacterium tumefaciens strain LBA 4404 was used instead of LBA 1119. Plantlets were maintained in tissue-culture on half-strength MS-medium, $10 \mathrm{~g}^{-1}$ sucrose medium before observations in CLSM, or transferred to the greenhouse where they were grown at $28{ }^{\circ} \mathrm{C}$ under a 16 -h photoperiod and $85 \%$ humidity. Inductions with $20 \mu \mathrm{M}$ dexamethasone were performed on $\mathrm{T}_{0}$ plantlets or 10-day-old $\mathrm{T}_{1}$ seedlings. CLSM studies were performed on $80 \mu \mathrm{m}$ thick vibratome sections of fresh material.

\section{Results}

Localization of GFP-tagged KNOX proteins in transient assays using onion epidermal peels

Particle bombardment of DNA-coated gold or tungsten particles on onion adaxial epidermal 
peels is a model system for studying subcellular localization of different proteins fused to marker proteins like GFP or $\beta$-glucuronidase (Quaedvlieg et al., 1998; Nakajima et al., 2001). We have used this transient assay to study the subcellular localization of three KNOX class-1 homeodomain proteins from rice, known as Oskn1, Oskn2 and Oskn3 (Postma-Haarsma et al., 1999). For the transient assays, $\mathrm{N}$ - or C-terminal GFP fusions of the KNOX genes were expressed under control of the CaMV 35S promoter. Observations of these GFP-tagged KNOX proteins were made using a fluorescence or confocal laser-scanning microscope.

Based on their subcellular localization patterns, the rice KNOX proteins could be divided into two groups, one consisting of Oskn2 and Oskn3, the other of Oskn1. N- or C-terminally GFP-tagged Oskn 2 and Oskn 3 could be detected in the nucleus and in cell wall aligned cytoplasm or cytoplasmic strands (Figure 1C and D). This localization pattern was found in multiple independent bombardment experiments, with variation in the abundance of cytoplasmic strands. Both N- or C-terminally GFP-tagged Oskn1 showed two localization patterns. In most cases the localization was similar to that described for Oskn2 and Oskn3
(Figure 1A). However, in approximately $15 \%$ of the cells $(n=1989)$, the GFP signal was found both in the nucleus and in small vesicle-like structures in the cytoplasm (Figure 1B). The nature of these vesicle-like structures is still unknown, but they are commonly referred to as punctae (Crawford and Zambryski 2001). The punctate localization pattern of GFP-tagged Oskn1 was compared to the localization pattern of GFP fused to an ER-targeting signal and the two patterns did not overlap (data not shown). Nuclear localization of the GFP-tagged proteins was confirmed by overlapping signal with a nucleic acid stain (DAPI). N-terminally GFP-tagged rice Oshox1 (Meijer et al., 1997), a different type of homeodomain protein, was used for comparison. In contrast to the partial nuclear localization pattern of the GFP-tagged KNOX proteins, GFP-tagged Oshox 1 protein localized exclusively to the nucleus $(n=286$, Figure 1E). Identical localization results were obtained for GFP fused to an NLS (data not shown), whereas an unmodified GFP was found to be equally divided over cytoplasm and nucleus (Figure $1 \mathrm{~N}$ ). Because $\mathrm{N}$ - or C-terminally GFPtagged KNOX proteins gave identical localization patterns and because N-terminally tagged KN1 was shown to be functional (Kim et al., 2003),
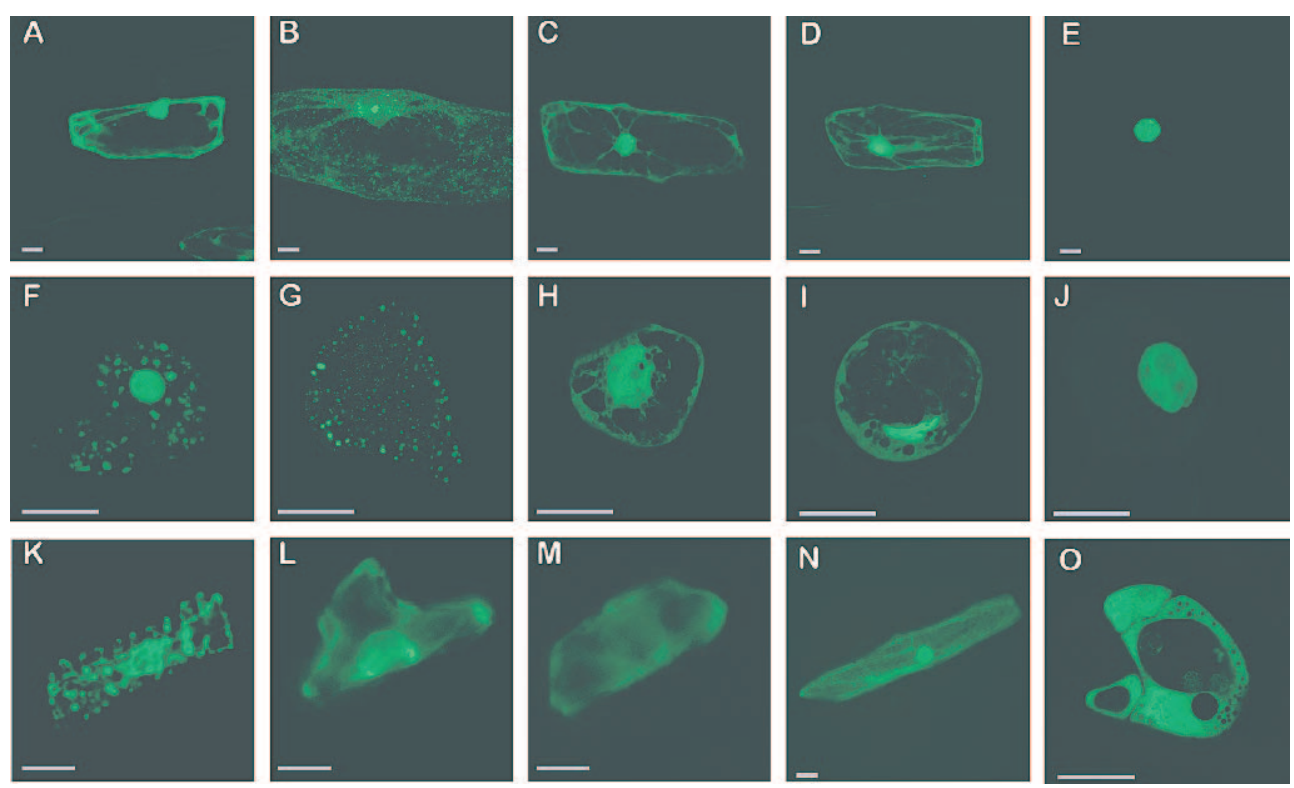

Figure 1. Subcellular localization of GFP-tagged KNOX proteins in transient bombardment assays. (A-E and N) Onion epidermal peels. (F-J and O) Rice suspension cells. (K-M) Rice epidermal leaf cells. Bombarded cells expressing GFP-tagged Oskn1 (A, B, F, G, $\mathrm{K}-\mathrm{M}$ ), expressing GFP-tagged Oskn2 (C and H), or expressing GFP-tagged Oskn3 (D and I). (E) Expression of GFP-tagged Oshox1. (J) Expression of NLS-GFP. (N and O) Expression of GFP. (Bar $=50 \mu \mathrm{m})$. 
subsequent experiments were performed only with $\mathrm{N}$-terminally GFP-tagged proteins.

\section{Localization of GFP-tagged KNOX in transient} assays using rice suspension cells and leaf epidermis

Transient assays with the GFP-tagged KNOX constructs were performed in rice suspension cells to study subcellular localization in the homologous system. Localization patterns were compared to those of GFP tagged with an NLS (Figure 1J) and unmodified GFP (Figure 1O), which, respectively, showed a nuclear and a largely cytoplasmic localization. The localization patterns of Oskn2 and Oskn 3 resembled the localization in onion epidermal cells in that the GFP-tagged proteins were mainly found in the nucleus and cytoplasm of the cells (Figure $1 \mathrm{H}$ and I). In all cases, GFPtagged Oskn1 showed a different localization pattern than GFP-tagged Oskn2 and Oskn3. GFPtagged Oskn1 protein was observed in a punctate localization, in most cases combined with a nuclear localization (in 21 of 26 cells, Figure $1 \mathrm{~F}$ and $\mathrm{G})$.

Subsequently, the expression constructs for GFP-tagged KNOX proteins were bombarded into rice leaves to study tissue specificity of the localization patterns. Three representative cells of a bombarded adaxial leaf epidermis are shown in Figure $1 \mathrm{~K}, \mathrm{~L}$ and $\mathrm{M}$, each displaying a different localization pattern of the GFP-tagged Oskn1 pro- tein. In the cell shown in Figure $1 \mathrm{~K}$, the protein is collected in punctae, in the cell shown in Figure 1L the protein is present in both nucleus and cytoplasm, and in the cell shown in Figure 1M the protein is observed only in the cytosol. Thus, the subcellular localization pattern of Oskn1 varied from cell to cell, not only with respect to the presence or absence of punctae, but also with respect to nuclear localization or exclusion. GFPtagged Oskn2 and Oskn3 proteins also showed variability with respect to nuclear or cytoplasmic localization in different cells of rice leaves (data not shown). Like in onion cells and rice suspension cells, GFP-tagged Oskn2 and Oskn3 proteins never showed the punctate localization pattern in rice leaves.

Stable transformation of Arabidopsis and rice with GFP-tagged KNOX constructs

To study the subcellular localization of rice KNOX proteins in various cell types in planta, the GFP-tagged KNOX expression constructs were stably transformed into Arabidopsis and rice. A majority of the Arabidopsis plants in the T1-population were stunted and had lobed leaves (Figure 2E-G), which in severe cases contained ectopic stipules in the leaf sinuses. The phenotypes resembled those of plants overexpressing the untagged rice KNOX genes (Figure 2A-C) or of plants overexpressing the Arabidopsis KNOX
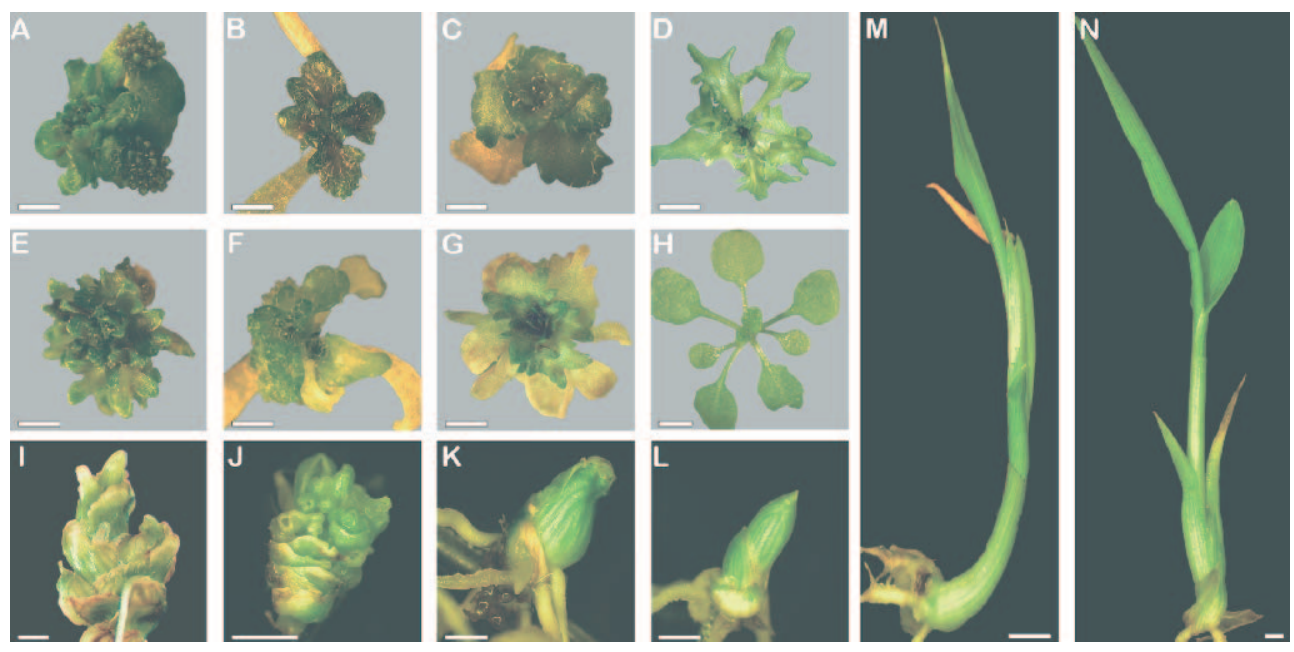

Figure 2. KNOX overexpression phenotypes. (A-D) Arabidopsis seedlings expressing untagged Oskn1 (A), Oskn2 (B), Oskn3 (C) and KNAT2 (D). (E-G) Arabidopsis seedlings expressing GFP-tagged Oskn1 (E), Oskn2 (F) and Oskn3 (G). (H) Wild type Arabidopsis seedling. (I-M) Primary transformants of rice expressing untagged Oskn3 (I), or GFP-tagged Oskn1 (J and K), Oskn2 (L) and Oskn3 (M). (N) Wild type rice seedling. $(\mathrm{Bar}=0.2 \mathrm{~cm}(\mathrm{~A}-\mathrm{L})$ or $0.4 \mathrm{~cm}(\mathrm{M}$ and $\mathrm{N})$ ). 
genes KNAT2 and STM (Figure 2D and Lincoln et al., 1994; Serikawa et al., 1996). In rice, ectopic expression of the GFP-tagged KNOX genes produced similar phenotypes as those observed upon overexpression of the untagged KNOX genes (Postma-Haarsma et al., 1999). These ranged from mild leaf phenotypes, showing a displacement of sheath tissues into the blade region, to severe phenotypes, where the leaves were completely transformed into sheath-like tissues (Figure 2I). GFP-tagged Oskn1 and Oskn2 produced both mild (not shown) and severe phenotypes (Figure $2 \mathrm{~J}-2 \mathrm{~L}$ ), similar to the untagged KNOX genes. However, in the case of GFP-tagged Oskn3 only mild overexpression phenotypes were found (Figure 2M), whereas overexpression of untagged Oskn3 also produced severe phenotypes. In conclusion, although the activity of the Oskn3 protein seemed to be somewhat attenuated, the large similarity between the phenotypes produced by GFP-tagged KNOX and those produced by untagged KNOX proteins in both Arabidopsis and rice, indicated that the functionality of the KNOX proteins was not affected by GFP-tagging.

\section{GFP-tagged KNOX localization patterns in stably transformed Arabidopsis plants}

In the root hairs of Arabidopsis plants ectopically expressing GFP-tagged Oskn2 or Oskn3, the GFP signal was observed in the nucleus and in the cytoplasm at the periphery of the cell (Figure $3 \mathrm{~F}$ and $\mathrm{G}$ ), a pattern different from the largely cyto- plasmic distribution of unmodified GFP (Figure 3H). A similar nuclear and cytoplasmic localization pattern could be observed in an ectopic stipule (Figure 3I) and in a lateral root meristem (Figure 3J) formed on an Arabidopsis plant expressing GFP-tagged Oskn2 . In the proximal parts of the root, the localization of GFP-tagged Oskn2 and Oskn3 proteins was mainly nuclear, with only a trace of signal in the cytoplasm. However, in the cortex tissue, localization patterns were different in the sense that the signal was not present in the nucleus. In Figure 3E both types of localization can be seen in one root tip. In the cortex cells the GFP signal is present throughout the cytoplasm of the cells, with a dark hole at the position of the nucleus. A bright ring surrounding this region without GFP is possibly the nuclear envelope where the GFP-tagged protein accumulates.

Within the population of cells showing a combined nuclear and cytoplasmic localization of the GFP-tagged KNOX proteins, fluctuations could be seen in the ratio between fluorescence present in the nucleus and in the cytoplasm. For example, the signal of GFP-tagged Oskn2 in cells of the root epidermis was found mainly in the nucleus, whereas the signal was more spread over the entire cell in the stele (Figure 3D).

In plants ectopically expressing GFP-tagged Oskn1, both punctate and non-punctate localization patterns of the protein were observed, similar to the results of transient assays. In root hairs, root cap cells and root epidermal cells, the protein was either found in the nucleus and the cytoplasm
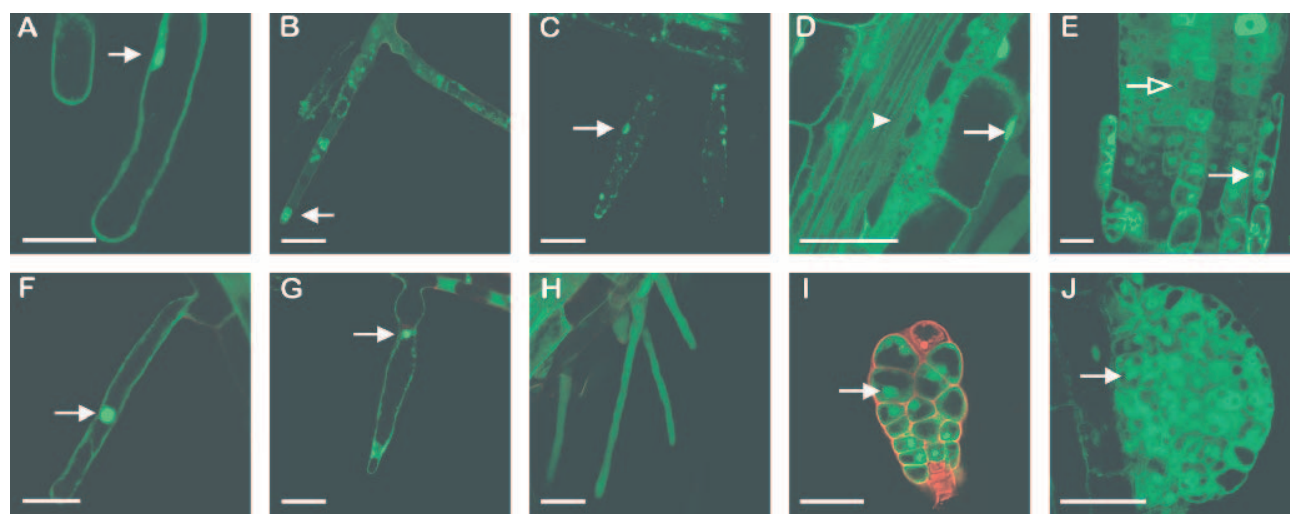

Figure 3. Stably transformed Arabidopsis seedlings expressing GFP-tagged KNOX proteins from rice. (A-C, F-H) Expression in root hairs of GFP-tagged Oskn1 (A and B), Oskn2 (F) and Oskn3 (G) and of ER-targeted GFP (C) or GFP (H). (D, E, I) Expression of GFP-tagged Oskn2 in the stele and root cortex (D), in the root tip (E) or in an ectopic stipule (I). (J) Expression of GFP-tagged Oskn1 in an adventitious root meristem. Arrows indicate GFP signal in nuclei, arrow heads indicate cytoplasmic localization of GFP signal and open arrows indicate nuclei without GFP signal. $(\mathrm{Bar}=50 \mu \mathrm{m})$. 
(Figure 3A) like the GFP-tagged Oskn2 and Oskn3 proteins, or the protein was localized in the nucleus and in punctae (Figure 3B). Comparison of the localization of the punctae with the pattern of GFP fused to an ER-targeting signal (Figure 3C) showed that the punctae were different from the ER-compartment or from fusiform bodies associated with the ER (Hawes et al., 2001). Furthermore, the Oskn1 punctae moved more randomly in the cytosol than the ER-associated fusiform bodies. In the cortex, the localization of GFPtagged Oskn1 protein was similar to that of GFP-tagged Oskn2 and Oskn3, namely mainly cytoplasmic and absent from the nucleus. A punctate localization was never observed in these cells.

GFP-tagged KNOX proteins in transgenic rice plants

In rice root tips ectopically expressing GFP-tagged KNOX proteins, the localization of the proteins was similar as in Arabidopsis roots. Like in
Arabidopsis, the appearance of punctae with GFPtagged Oskn 1 showed variability. In rice plants, a punctate localization was often found in one root tip but was not seen in other root tips of the same plant (Figure $4 \mathrm{~J}$ and $\mathrm{K}$ ).

In the SAM, GFP-tagged proteins mainly accumulated in the nucleus and only few traces of fluorescence were observed in the cytoplasm. However, because the shoot phenotypes resulting from overexpression of GFP-tagged KNOX proteins were very severe, it was possible that the localization patterns did not reflect the wild type situation. To circumvent this problem, we used a glucocorticoid-inducible system for ectopic expression of the GFP-tagged KNOX proteins (Ouwerkerk et al., 2001). Two weeks of dexamethasone induction of plantlets bearing the inducible expression constructs produced similar phenotypes as constitutive ectopic expression of KNOX genes (Figure 4A). Non-induced plantlets and plantlets induced for only 2 days had a normal appearance. After 2 days of induction the intracellular locali-
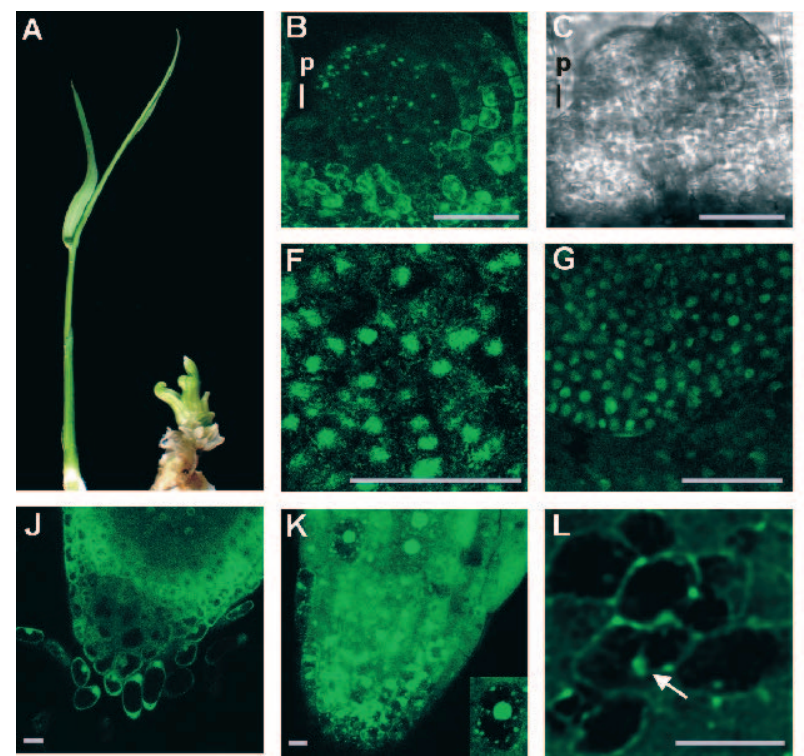
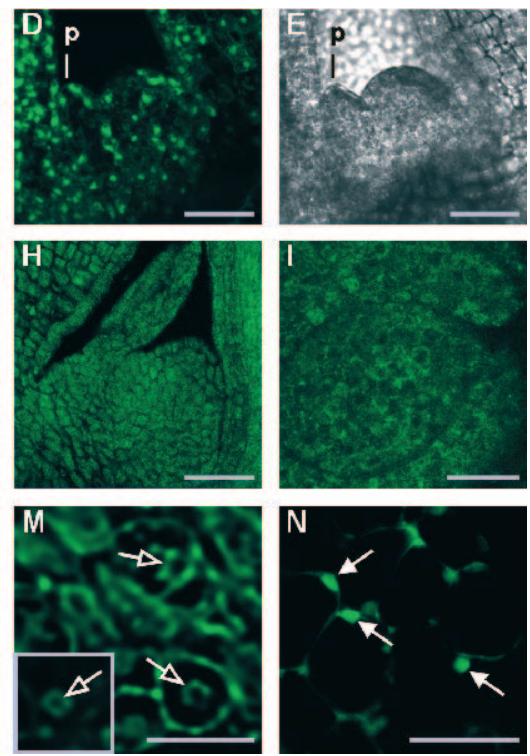

Figure 4. Stably transformed rice plantlets expressing GFP-tagged KNOX proteins. (A-I) Dexamethasone-induced expression. (J-N) Constitutive expression. (A) Plantlets expressing GFP-tagged Oskn1 after 2 weeks induction with dexamethasone (right) or without induction (left). (B-I) Induced expression of GFP-tagged KNOX proteins after 2 days on medium containing dexamethasone (B-E). Longitudinal SAM sections of two plantlets expressing GFP-tagged Oskn1, showing GFP signal (B and D) and reflected light image (C and $\mathrm{E})$. The plantlet in $\mathrm{B}$ and $\mathrm{C}$ shows an earlier stage of primordium (p) development than the plantlet in $\mathrm{D}$ and $\mathrm{E}$. (F and $\mathrm{G})$ Transverse SAM sections expressing GFP-tagged Oskn1 (F) or expressing GFP-tagged Oskn2 (G). (H and I) SAM expressing GFP in longitudinal $(\mathrm{H})$ and transverse section $(\mathrm{I})$. ( $\mathrm{J}$ and $\mathrm{K}$ ) Root tips ectopically expressing GFP-tagged Oskn1 with nuclear/cytoplasmic (J) and punctate $(\mathrm{K})$ localization pattern (detail in inset in $\mathrm{K}$ ). (L-N) Calli ectopically expressing GFP-tagged Oskn2 grown for $24 \mathrm{~h}$ on medium without hormones (L), medium containing $1 \mu \mathrm{M}$ 1-NAA (M), $10 \mu \mathrm{M} \mathrm{GA}_{3}$ (inset in M), and medium containing $1 \mu \mathrm{M}$ NPA (N). Arrows indicate GFP signal in nuclei, open arrows indicate nuclei without GFP signal. $(\mathrm{Bar}=50 \mu \mathrm{m})$. 
zation of GFP-tagged KNOX protein in cells of the SAM was analyzed in transverse and longitudinal vibratome sections. The GFP-tagged proteins of Oskn1, Oskn2 and Oskn3 showed a uniform subcellular localization pattern in cells of the SAM, being present mainly in the nucleus (Figure $4 \mathrm{~B}, \mathrm{D}, \mathrm{F}$ and $\mathrm{G}$ and data not shown), whereas unmodified GFP was mainly observed in the cytoplasm (Figure 4H and I). The nuclear localization of GFP-tagged KNOX proteins in the SAM was confirmed by overlapping signals with the nucleic acid stain DAPI (data not shown). A punctate localization of the GFP-tagged Oskn1 protein was never observed in cells of the SAM.

For GFP-Oskn1, a series of plantlets was analyzed to determine the localization pattern at different stages of leaf primordium development. In leaf primordia at an early stage of development, we could not observe any fluorescent signal of the GFP-tagged Oskn1 protein (Figure 4B and C), while leaf primordia at later stages of development showed a nuclear localization of the signal of GFP-Oskn1 (Figure 4D and E). These observations indicate a post-transcriptional regulation mechanism, because the dexamethasone-inducible promoter system is active during all stages of primordium development (Ouwerkerk et al., 2001).

\section{Influence of hormones on subcellular localization of KNOX gene products}

To study the possible influence of hormones on the subcellular localization of KNOX gene products, Arabidopsis seedlings overexpressing GFP-tagged KNOX proteins or unmodified GFP were grown on media containing 2,4-D, $\mathrm{GA}_{3}$, BAP, 1-NAA, and the auxin-transport inhibitor NPA. For plants transformed with GFP-tagged Oskn1, treatment with hormones could not trigger all root tip cells to form punctae, nor did it lead to a cytoplasmic and nuclear localization of the protein in all root tip cells. In root hairs, however, application of $\mathrm{GA}_{3}$ and 1-NAA resulted in a disappearance of the punctae for GFP-tagged Oskn1 and localization of the protein in the cytoplasm. Treatment with NPA, 2,4-D or BAP did not affect the punctate localization of the GFP-tagged Oskn1 protein in three independent experiments. Application of any of the mentioned hormones never triggered the appearance of punctae in plants ectopically expressing GFP-tagged Oskn2 or Oskn3.
Application of NPA shifted the distribution of GFP-tagged KNOX protein toward accumulation in the nucleus (data not shown).

Hormone effects were also examined in rice calli transformed with expression constructs for GFP-tagged KNOX proteins. The calli, which are normally maintained on a medium containing 2 , 4-D, were starved for 2,4-D for 2 weeks before transfer to media with different hormones. In these hormone-starved calli, GFP-tagged Oskn2 was present in the cytoplasm and in the nucleus (Figure 4L). In control cells transformed with GFP, the signal was mainly found in the cytoplasm (not shown). Upon application of various hormones, the localization pattern of GFP-tagged Oskn2 was altered, while the pattern of GFP remained the same. Four hours after the application of $\mathrm{GA}_{3}$ or 1-NAA, the signal of the GFPtagged Oskn2 protein was no longer detectable in the nucleus, but only in the cytoplasm and in the nuclear envelope (Figure 4M). Application of NPA led to a nuclear concentration of the GFPtagged proteins (Figure 4N). Application of 2,4-D and BAP had no effect on the subcellular localization of the GFP-tagged Oskn2 proteins in calli (data not shown). The same effects of hormonal treatments were observed on the localization of GFP-tagged Oskn3 protein (data not shown). In hormone-starved calli expressing GFP-tagged Oskn1, a majority of the cells showed a punctate localization, in some cases combined with a nuclear localization. Application of 2,4-D or BAP did not influence this localization pattern. However, upon application of $\mathrm{GA}_{3}, 1$-NAA and NPA the punctae disappeared (data not shown).

\section{Cell-to cell trafficking of rice KNOX proteins}

In several independent bombardment assays using onion epidermal cells, the GFP-tagged KNOX proteins were frequently observed in groups of more than two connecting cells (129 out of 1009 observations for GFP-Oskn1, 110 out of 981 for GFP-Oskn2 and 14 out of 336 for GFP-Oskn3; Figure 5A and E). The size of these groups measured up to 24 cells for GFP-Oskn1, up to 14 cells for GFP-Oskn2 and up to five cells for GFPOskn3. It is unlikely that these groups could result from the possibility that neighboring cells were hit in the bombardment, because the unmodified GFP control protein was always observed in 

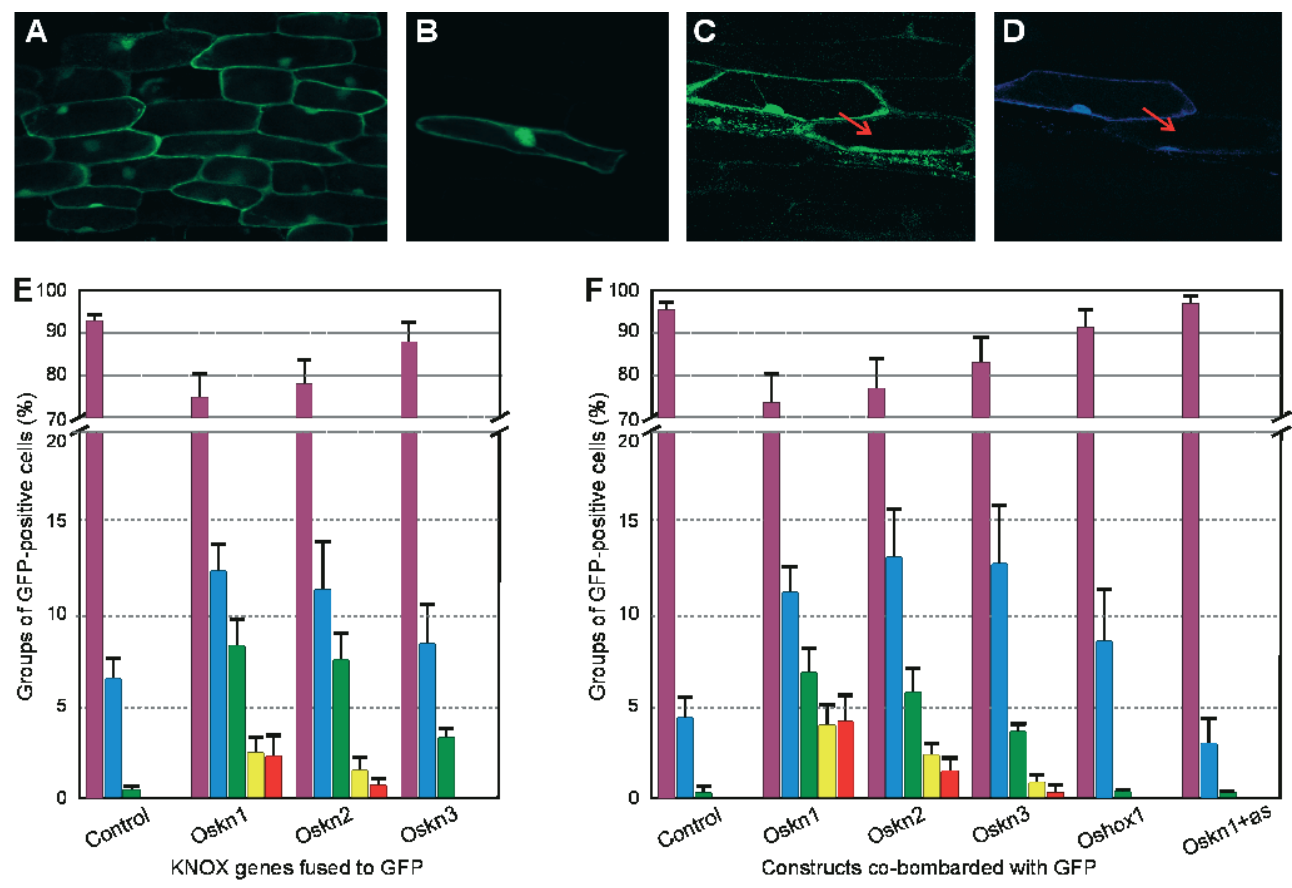

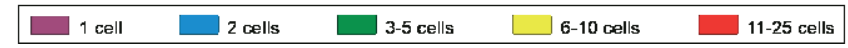

Figure 5. Trafficking of KNOX proteins in transient assays. (A) Large group of cells expressing GFP-tagged Oskn1 as a result of trafficking. (B) Single cell expressing GFP-tagged Oskn2. (C and D) Co-trafficking of blue fluorescent protein (BFP) with GFP-tagged Oskn1 from a bombarded cell to an adjacent cell demonstrated by observation with GFP-filter (C) and BFP-filter (D). Arrow indicates the trafficking direction of the proteins. (E and F) Onion epidermal peels bombarded with GFP-tagged KNOX expression constructs (E) or co-bombarded with mixtures of GFP and KNOX expression constructs (F). Groups of different numbers of adjacent GFPpositive cells $(1,2,3-5,6-10$ or 11-25 cells) were scored and are presented as percentage \pm s.e.m. of the total number of GFP-positive groups. Average data of three (E) or six (F) independent and representative experiments are shown. The control construct was the empty expression vector as used for expression of the KNOX genes and Oshox1. For [Oskn1 + as] a $1: 1$ mixture of sense and antisense Oskn1 expression constructs was used. Statistical significance of the differences between Oskn1, Oskn2 and Oskn3 was determined by one-way analysis of variance (ANOVA) followed by Bonferroni's test. In both E and F, the difference in trafficking to groups of 11-25 cells is significant at $0.01<P<0.05$ for the comparison of Oskn1 with Oskn2 and at $P<0.01$ for the comparison of Oskn1 with Oskn3. The difference between Oskn2 and Oskn3 in F is not significant.

single cells or in two adjacent cells and only exceptionally in a group of three cells (one out of 665 observations). Therefore, these data strongly suggested the occurrence of cell-to-cell trafficking of the GFP-tagged KNOX proteins.

The bombardment experiments using the GFPtagged KNOX proteins suggested differences in the trafficking abilities of the KNOX proteins, with Oskn1 showing the most extensive spread to neighboring cells and Oskn3 showing the most limited trafficking. However, we considered that an assay using the unmodified KNOX proteins would allow a better evaluation of possible differences in trafficking abilities. In Figures 5C and $\mathrm{D}$ the co-trafficking of the marker protein Blue Fluorescent Protein (BFP) with GFP-tagged Oskn1 is shown. This inspired us to develop an assay where the trafficking of untagged KNOX proteins is visualized by means of the co-trafficking of separate GFP or BFP marker proteins. By counting the numbers of neighboring cells with GFP expression, the trafficking abilities of KNOX gene products were quantified. The co-bombardment experiments were performed six times and the averages are shown in Figure 5F. As controls, GFP was bombarded alone or co-bombarded with the empty expression vector that was used for the KNOX expression constructs. In none of the six experiments, GFP-positive groups larger than three neighboring cells were observed for these controls (1252 observations pooled in Figure 5F, Control). The same was true for co-bombardment of GFP with the homeodomain protein Oshox1 that does not belong to the KNOX family. In 
contrast, following the co-bombardment of GFP and Oskn1, we could see GFP-positive groups of up to 25 cells in all experiments performed, indicating that the Oskn1 protein is able to traffic to many neighboring cells, thereby allowing the co-trafficking of GFP. The percentages of groups consisting of 11 to 25 cells varied between 2.1 and $7.3 \%$ in separate experiments, with an average of $4.2 \%$ over six experiments (112 out of 2646 observations). Oskn1 trafficked to a larger extent than the other KNOX proteins. The average percentage of GFP-positive groups of 11-25 cells in co-bombardment experiments of GFP with Oskn2 was only $1.5 \%$ (38 out of 2529 observations; different from Oskn1 at $P<0.05$ ) and $0.3 \%$ for Oskn3 (seven out of 2240 observations; different from Oskn1 at $P<0.01$; difference with Oskn2 not significant). Among the three KNOX proteins, Oskn3 appeared to traffick to the most limited extent, as also groups of 3-5 and 6-10 cells were less frequently observed. Still, the GFP-positive sectors observed in co-bombardment experiments with the untagged Oskn3 protein were significantly larger than those observed with GFP-tagged Oskn3, indicating that GFP tagging can have a negative effect on the trafficking properties of KNOX proteins. To provide further evidence that the trafficking of GFP in the co-bombardment experiments was dependent on the presence of KNOX gene products, an antisense Oskn1 construct was included in the bombardment mixture. To demonstrate that the antisense construct blocked Oskn1 production, a mixture of GFP-tagged Oskn1, anti-sense Oskn1 and BFP was used in an onion bombardment experiment. Many single cells expressed BFP (36 out of 39 observations), but none of them expressed GFP, indicating the absence of the GFP-tagged KNOX protein. Finally, in a co-bombardment of GFP with untagged Oskn1 and antisense Oskn1, no GFPpositive sectors larger than two to three cells were found in 452 observations, indicating that Oskn1 expression is required for cell-to-cell movement of GFP (Figure 5F, Oskn1 + as).

\section{Discussion}

In this study we analyzed the properties of three different KNOX class1 homeodomain proteins from rice with respect to their subcellular locali- zation and trafficking properties. Subcellular localization was studied by particle bombardment of onion epidermal peels, rice calli and rice leaves and by stable transformation of Arabidopsis and rice with constitutive and inducible overexpression constructs of GFP-tagged KNOX genes. In all test systems, the localization of GFP-tagged Oskn1 varied between different cells, displaying either a distribution over punctae or a presence in both nucleus and cytoplasm. In contrast, Oskn2 and Oskn3 showed a nuclear and cytoplasmic localization in all systems tested. For all examined KNOX proteins, the ratio between nuclear localized and free cytoplasmic protein showed variation between tissues. The observation that differences in localization patterns between Oskn1 and Oskn2/Oskn3 proteins were consistent in all systems used, suggests a conserved regulatory mechanism for subcellular localization of the KNOX proteins in onion, rice and Arabidopsis.

The punctae displayed by GFP-tagged Oskn1 in different test systems, have also been observed for GFP-tagged KN1 (Kim et al., 2003). GFP fused to the cucumber mosaic virus $3 \mathrm{a}$ movement protein also showed a punctate localization (Itaya et al., 1998). Punctae formed by this movement protein were associated with plasmodesmata inside the cell wall. However, in our assays the punctae were not present inside the cell wall, but in the cell wall aligned cytoplasm. Moreover, the Oskn1 punctae moved at random in the cytoplasm of cells of all tested species, arguing against the possibility that they represent plasmodesmata. The punctae also did not appear to represent an ER-compartment as there was no overlap with the localization pattern of GFP fused to an ER-targeting signal. It is possible that the punctae might represent a vacuolar storage compartment. Furthermore, it cannot be excluded that the punctae are an artifact of the overexpression system and that their typical association with Oskn1 expression reflects a difference in protein stability with the other KNOX proteins.

Regulation of nuclear localization is a wellrecognized mechanism to control the functionality of transcription factors and other regulatory proteins. The importance of this mechanism with respect to the control of KNOX activity in the SAM is still unknown. In our studies, a subcellular localization other than nuclear was mainly found in cells where the KNOX genes are normally not 
expressed, whereas in the SAM, a nuclear localization was found for all three KNOX genes examined. Therefore, nuclear exclusion of KNOX proteins, which interferes with their function as transcription factors, could play a role as a safety mechanism in the establishment of KNOX expression domains. Such a safety mechanism can be expected, considering that the severe consequences of misexpression of KNOX genes require a tight control system.

The subcellular localization patterns of Oskn1, Oskn2 and Oskn3 changed upon treatment with hormones. The localization of Oskn1 protein in punctae was lost upon application of $\mathrm{GA}_{3}$ or 1-NAA. Furthermore, application of $\mathrm{GA}_{3}$ or 1-NAA resulted in exclusion of all three KNOX proteins from the nucleus. It has been shown that KNOX gene expression in the SAM represses the activity of a GA biosynthetic enzyme, GA20-oxidase, implicating that increased GA production can occur in the leaf primordia where KNOX gene expression is down-regulated (Sakamoto et al., 2001; Hay et al., 2002, 2004). Therefore, our observation that $\mathrm{GA}_{3}$ induces the nuclear exclusion of KNOX proteins fits well with our hypothesis that regulation of nuclear localization could represent a safety mechanism to ensure tight control of KNOX activity. In this scenario, the down-regulation of KNOX gene expression in founder cells of leaf primordia would induce GA production, which in turn would induce the nuclear exclusion of any remaining KNOX protein. As a result, all KNOX activity would be prevented and primordia outgrowth allowed. Likewise, the 1-NAA-induced nuclear exclusion that we observed could help to prevent KNOX activity during primordium initiation. This is in perfect agreement with data showing that sites where auxin accumulates as a result of polar auxin transport in the SAM, define the position of future primordia (Reinhardt et al., 2000, 2003; Scanlon, 2003). To find support for our hypothesis, we used our transgenic lines containing a dexamethasone-inducible GFP-tagged Oskn1 construct to examine KNOX protein localization during leaf primordium development. Despite the fact that the inducible promoter is active at all stages of primordium development (Ouwerkerk et al., 2001), we found that no GFP-Oskn1 protein was detectable during early stages of primordium development, while the protein showed a nuclear localization at later stages. These observations do not provide direct evidence for a hormone-dependent nuclear exclusion mechanism, but they indicate the presence of a post-transcriptional control mechanism that operates at a critical early stage of primordium development and might involve nuclear exclusion and protein degradation.

The subcellular localization of the KNOX proteins was also affected upon application of the polar auxin transport inhibitor, NPA, which induced a nuclear accumulation in root tips and calli. As this change in localization pattern was opposite to the effect of 1-NAA application, it might be directly related to the absence of auxin. On the other hand, inhibition of polar auxin transport by NPA has been suggested to occur through inhibition of intracellular relocation of membrane proteins (Geldner et al., 2001). Therefore, the inhibition of this process by NPA could hamper nuclear export and affect KNOX protein localization.

To study intercellular trafficking of KNOX proteins we have designed a new set-up for the transient assays, using a co-bombardment assay of GFP and untagged KNOX constructs. The so obtained data were complementary to the data obtained by bombardment of GFP-tagged KNOX constructs. Although the functionality of the GFPtagged KNOX proteins was confirmed by showing that they produce similar overexpression phenotypes as the untagged KNOX proteins, a negative influence of the GFP-tag could be observed in the trafficking assays. The use of untagged proteins allowed us to study the protein properties in a more natural way. In this new set-up, sGFP(S65T) was used as a cell-autonomous marker. However, other researchers reported GFP to behave non-cell autonomously. This difference could be due to the type of GFP used, as for example, mGFP5 and mGFP6 have been reported to traffic extensively (Siemering et al., 1996; Kim et al., 2002b). Another explanation could lie in differences in experimental set-up. In our study, epidermal peels were removed before bombardment and cultured as a single layer, whereas others bombarded complete bulb-scales and isolated the epidermis upon observation. The thick cuticula present on the adaxial side of the epidermis requires a higher impact of the particles to enter the cells than is necessary for bombardment of the abaxial side where no waxy cuticula is present. Therefore, we 
preferred to remove the epidermis and bombard its abaxial side in order to minimize wounding, leakage and stress-reactions in the onion cells.

In large scale transient assays on onion epidermal cells, the Oskn1 protein frequently trafficked to groups of up to 25 neighboring cells, while Oskn2 showed a more limited trafficking behavior and Oskn3 trafficked to an even lower extent. This difference in trafficking ability was observed both using GFP-tagged KNOX proteins and using our co-bombardment assay of untagged KNOX proteins with GFP marker protein. It is not likely to be due to size-differences of the proteins, because all three KNOX proteins have similar sizes. It is possible that a connection exists between the fact that Oskn1 is the only rice KNOX gene to form punctae and that it is the one to traffic most extensively. However, the extended trafficking ability of Oskn1 is not dependent on the formation of punctae since trafficking of the protein was also found in cases of nuclear and cytoplasmic Oskn1 localization. Kragler et al. (2000) showed that a peptide antagonist of the KN1 protein could inhibit the dilation of plasmodesmata, which consequently inhibited trafficking of $\mathrm{KN} 1$ protein and reduced co-trafficking of dextran. In Figure 6 the homology of Oskn1 to KN1 in the antagonist region is shown, whereas Oskn2 and Oskn3 show less similarity. The differences in sequence homology in this region involved in dilation of the plasmodesmata, could be the cause of the differences in trafficking capacity between the three rice KNOX proteins. Besides this region also the homeodomain, present in all three KNOX proteins, is known to be involved in trafficking of the proteins (Lucas et al., 1995). A deletion of three amino acids in the homeodomain of KN1

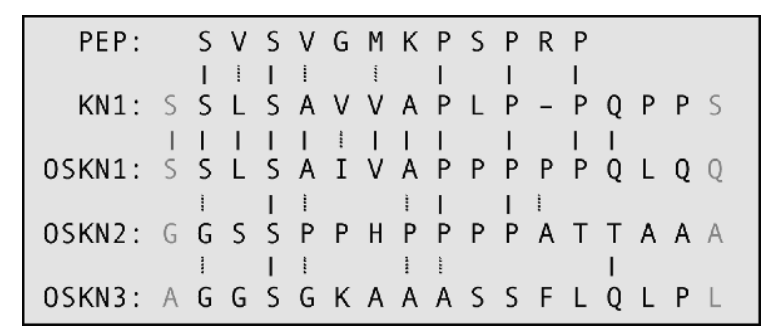

Figure 6. Sequence homology in the region of 14 amino acids involved in SEL dilation of KN1 from maize and the corresponding regions of the rice KNOX proteins Oskn1, Oskn2 and Oskn3. Also included is the $\mathrm{KN} 1$ antagonist identified by Kragler et al. (2000). reduced cell-to-cell transport of FITC-labeled KN1.

Cell-to-cell trafficking of proteins can occur in a targeted and a non-targeted fashion. Wu et al. (2003) suggested that cell-to-cell movement of transcription factors results from free diffusion in a non-targeted fashion (Wu et al., 2003). On the other hand, Sessions et al. (2000) showed that two independent transcription factors can traffic long and short ranges in a targeted fashion. For nontargeted proteins it has been shown that subcellular localization determines their availability for cell-to-cell movement (Crawford and Zambryski, 2000). The data presented here support the notion that cell-to-cell movement of the KNOX class 1 proteins is an active process triggered by the proteins themselves. This was confirmed by an antisense approach in which knock-down of Oskn1 gene expression inhibited cell-to-cell movement of Oskn1 protein and of the GFP marker protein to neighboring cells. Therefore, Oskn1 appeared to be required for its own trafficking and the co-trafficking of an unrelated marker protein, indicating that trafficking occurs in a targeted fashion.

Our localization and trafficking data of KNOX class 1 homeodomain proteins from rice fit well with other data regarding differences between KNOX class 1 proteins. Based on their expression patterns, KNOX class 1 homeobox genes can be divided into two subclasses. Genes in one subclass are expressed throughout the central zone of the SAM, whereas the expression of genes in the other subclass is confined to the borders of organ primordia. Expression in the central zone is shown for KNAT2 and STM from Arabidopsis (Long et al., 1996), knl from maize (Jackson et al., 1994) and Oskn1 (or its equivalent in other cultivars, OSH1) from rice (Matsuoka et al., 1993; PostmaHaarsma et al., 1999). Examples of genes showing the peripheral type of expression pattern are KNAT1 from Arabidopsis (Lincoln et al., 1994), rough sheath-1 and liguleless-4 from maize (reviewed by (Reiser et al., 2000) and $O s k n 2$ and $O s k n 3$ (or their equivalents in other cultivars, $\mathrm{OSH71}$ and $\mathrm{OSH} 15$ ) from rice (Sentoku et al., 1999; Postma-Haarsma et al., 2002). The differences between these two subclasses are also apparent from phenotypes of loss-of-function mutants. Mutations in Arabidopsis STM or maize $k n l$, both in the subclass with central zone expression, results in loss or 
premature termination of the SAM (Endrizzi et al., 1996; Kerstetter et al., 1997). Mutant analysis of KNAT1 (BREVIPEDICELLUS) in Arabidopsis and of $O S H 15$ in rice, both in the subclass with the peripheral type of expression, showed these genes to be involved in stem development in addition to SAM maintenance (Sato et al., 1999; Mele et al., 2003).

In conclusion, we have shown in this study that the subcellular localization patterns of three KNOX class 1 proteins from rice support the division of KNOX class 1 into two subclasses based on expression patterns and mutant analysis. Also the differences found in trafficking abilities of the three examined KNOX proteins favor this division. The differential regulation of the subcellular localization of KNOX proteins in both subclasses might represent a mechanism for the precise balancing of their activities. Our data suggest that this regulation is under hormonal control. Whether hormones also have a direct influence on the trafficking abilities of the KNOX proteins remains presently unknown. A major future challenge will be to gain understanding of the precise interactions between the KNOX proteins and plant hormones in plant development.

\section{Acknowledgements}

We thank Dr. D. Jackson and Dr. W. Werr for critically reading the manuscript and E. Schrijnemakers for plant care. The KNAT2 EST clone 240 N22 was kindly provided by the Arabidopsis Biological Resource Center and DNA Stock Center (Ohio State University, Columbus, USA). E.S. was supported by a European Commission TMR Marie Curie Research Training Grant (ERBFMBICT972716). P.B.F.O. was supported by the EU project CerealGeneTags (QLGT-CT-200101453).

\section{References}

Baurle, I. and Laux, T. 2003. Apical meristems: the plant's fountain of youth. Bioessays 25: 961-970.

Brand, U., Grunewald, M., Hobe, M. and Simon, R. 2002. Regulation of $C L V 3$ expression by two homeobox genes in Arabidopsis. Plant Physiol. 129: 565-575.

Chiu, W.L., Niwa, Y., Zeng, W., Hirano,T., Kobayashi, H. and Sheen J. 1996. Engineered GFP as a vital reporter in plants. Curr. Biol. 6: 325-330.
Clark, S.E. 2001a. Cell signalling at the shoot meristem. Nat. Rev. Mol. Cell Biol. 2: 276-284.

Clark, S.E. 2001b. Meristems: start your signaling. Curr. Opin. Plant Biol. 4: 28-32.

Clough, S.J. and Bent, A.F. 1998. Floral dip: a simplified method for Agrobacterium-mediated transformation of Arabidopsis thaliana. Plant J. 16: 735-743.

Crawford, K.M. and Zambryski, P.C. 2000. Subcellular localization determines the availability of non-targeted proteins to plasmodesmatal transport. Curr. Biol. 10: 1032-1040.

Crawford, K.M. and Zambryski, P.C. 2001. Non-targeted and targeted protein movement through plasmodesmata in leaves in different developmental and physiological states. Plant Physiol. 125: 1802-1812.

Endrizzi, K., Moussian, B., Haecker, A., Levin, J.Z. and Laux, T. 1996. The SHOOT MERISTEMLESS gene is required for maintenance of undifferentiated cells in Arabidopsis shoot and floral meristems and acts at a different regulatory level than the meristem genes WUSCHEL and ZWILLE. Plant J. 10: 967-979.

Fernandez, A.G., Long, J.A., Joy, R.E. and Barton, M.K. 2001. Rescue of the shootmeristemless (stm) mutant phenotype by expression of STM mRNA in a subset of its normal domain: implications for nonautonomous action of the STM transcription factor in Arabidopsis thaliana. Dev. Biol. 235: 260.

Geldner, N., Friml, J., Stierhof, Y.D., Jurgens, G. and Palme, K. 2001. Auxin transport inhibitors block PIN1 cycling and vesicle traficking. Nature 413: 425-428.

Gisel, A., Barella, S., Hempel, F.D. and Zambryski, P.C. 1999. Temporal and spatial regulation of symplastic trafficking during development in Arabidopsis thaliana apices. Development 126: 1879-1889.

Hake, S. 2001. Transcription factors on the move. Trends Genet. 17: 2-3.

Hake, S., Char, B.R., Chuck, G., Foster, T., Long, J. and Jackson, D. 1995. Homeobox genes in the functioning of plant meristems. Philos. Trans. R. Soc. Lond. Ser. B-Biol. Sci. 350: 45-51.

Hamant, O., Nogue, F., Belles-Boix, E., Jublot, D., Grandjean, O., Traas, J. and Pautot, V. 2002. The KNAT2 homeodomain protein interacts with ethylene and cytokinin signaling. Plant Physiol. 130: 657-665.

Haseloff, J., Siemering, K.R., Prasher, D.C. and Hodge, S. 1997. Removal of a cryptic intron and subcellular localization of green fluorescent protein are required to mark transgenic Arabidopsis plants brightly. Proc. Natl. Acad. Sci. 94: 2122-2127.

Hawes, C., Saint-Jore, C., Martin, B. and Zheng, H.Q. 2001. ER confirmed as the location of mystery organelles in Arabidopsis plants expressing GFP! Trends Plant Sci. 6: 245-246.

Hay, A., Kaur, H., Phillips, A., Hedden, P., Hake, S. and Tsiantis, M. 2002. The gibberellin pathway mediates KNOTTED1-type homeobox function in plants with different body plans. Curr. Biol. 12: 1557-1565.

Hay, A., Craft, J. and Tsiantis, M. 2004. Plant hormones and homeoboxes: bridging the gap? Bioessays 26: 395404.

Itaya, A., Woo,Y.M., Masuta, C., Bao, Y.M., Nelson, R.S. and Ding, B. 1998. Developmental regulation of intercellular protein trafficking through plasmodesmata in tobacco leaf epidermis. Plant Physiol. 118: 373-385. 
Jackson, D. 2002. Double labeling of KNOTTED1 mRNA and protein reveals multiple potential sites of protein trafficking in the shoot apex. Plant Physiol. 129: 1423-1429.

Jackson, D. and Kim, J.Y. 2003. Intercellular signaling: an elusive player steps forth. Curr. Biol. 13: R349-R350.

Jackson, D., Veit, B. and Hake, S. 1994. Expression of maize KNOTTED1 related homeobox genes in the shoot apical meristem predicts patterns of morphogenesis in the vegetative shoot. Development 120: 405-413.

Kerstetter, R.A., Laudencia-Chingcuanco, D., Smith, L.G. and Hake, S. 1997. Loss-of-function mutations in the maize homeobox gene, knotted1, are defective in shoot meristem maintenance. Development 124: 3045-3054.

Kim, I., Hempel, F.D., Sha, K., Pfluger, J. and Zambryski, P.C. 2002a. Identification of a developmental transition in plasmodesmatal function during embryogenesis in Arabidopsis thaliana. Development 129: 1261-1272.

Kim, J.Y., Yuan, Z.A., Cilia, M., Khalfan-Jagani, Z. and Jackson, D. 2002b. Intercellular trafficking of a KNOTTED1 green fluorescent protein fusion in the leaf and shoot meristem of Arabidopsis. Proc. Natl. Acad. Sci. 99: 4103-4108.

Kim, J.Y., Yuan, Z. and Jackson, D. 2003. Developmental regulation and significance of KNOX protein trafficking in Arabidopsis. Development 130: 4351-4362.

Kragler, F., Monzer, J., Shash, K., Xoconostle-Cazares, B. and Lucas, W.J. 1998. Cell-to-cell transport of proteins: requirement for unfolding and characterization of binding to a putative plasmodesmal receptor. Plant J. 15: 367-381.

Kragler, F., Monzer, J., Xoconostle-Cazares, B. and Lucas, W.J. 2000. Peptide antagonists of the plasmodesmal macromolecular trafficking pathway. EMBO J. 19: 2856-2868.

Kusaba, S., Fukumoto, M., Honda, C., Yamaguchi, I., Sakamoto, T. and Kano-Murakami,Y. 1998. Decreased $\mathrm{GA}(1)$ content caused by the overexpression of $\mathrm{OSH} 1$ is accompanied by suppression of GA 20-oxidase gene expression. Plant Physiol. 117: 1179-1184.

Lee, J.Y., Yoo, B.C., Rojas, M.R., Gomez-Ospina, N., Staehelin, L.A. and Lucas, W.J. 2003. Selective trafficking of noncell-autonomous proteins mediated by NtNCAPP1. Science 299: $392-396$

Lincoln, C., Long, J., Yamaguchi, J., Serikawa, K. and Hake, S. 1994. A KNOTTED1-like homeobox gene in Arabidopsis is expressed in the vegetative meristem and dramatically alters leaf morphology when overexpressed in transgenic plants. Plant Cell 6: 1859-1876.

Long, J.A., Moan, E.I., Medford, J.I. and Barton, M.K. 1996. A member of the KNOTTED class of homeodomain proteins encoded by the $S T M$ gene of Arabidopsis. Nature 379: $66-69$

Lucas, W.J. 1999. Plasmodesmata and the cell-to-cell transport of proteins and nucleoprotein complexes. J. Exp. Bot. 50: 979-987.

Lucas, W.J., Bouchepillon, S., Jackson, D.P., Nguyen, L., Baker, L., Ding, B. and Hake, S. 1995. Selective trafficking of KNOTTED1 homeodomain protein and its messengerRNA through plasmodesmata. Science 270: 1980-1983.

Maizel, A., Bensaude, O., Prochiantz, A. and Joliot, A. 1999. A short region of its homeodomain is necessary for engrailed nuclear export and secretion. Development 126: 3183-3190.

Matsuoka, M., Ichikawa, H., Saito, A., Tada,Y., Fujimura, T. and Kano-Murakami, Y. 1993. Expression of a rice homeobox gene causes altered morphology of transgenic plants. Plant Cell 5: 1039-1048.
Meijer, A.H., Scarpella, E., van Dijk, E.L., Qin, L., Taal, A.J.C., Rueb, S., Harrington, S.E., McCouch, S.R., Schilperoort, R.A. and Hoge, J.H.C. 1997. Transcriptional repression by Oshox1, a novel homeodomain leucine zipper protein from rice. Plant J. 11: 263-276.

Mele, G., Ori, N., Sato, Y. and Hake, S. 2003. The knotted1-like homeobox gene BREVIPEDICELLUS regulates cell differentiation by modulating metabolic pathways. Genes Dev. 17: 2088-2093.

Nakajima, K., Sena, G, Nawy, T. and Benfey, P.N. 2001. Intercellular movement of the putative transcription factor SHR in root patterning. Nature 413: 307-311.

Ormenese, S., Havelange, A., Deltour, R. and Bernier, G. 2000. The frequency of plasmodesmata increases early in the whole shoot apical meristem of Sinapis alba L. during floral transition. Planta 211: 370-375.

Ouwerkerk, P.B.F., de Kam, R.J., Hoge, J.H.C. and Meijer, A.H. 2001. Glucocorticoid-inducible gene expression in rice. Planta 213: $370-378$.

Perbal, M.C., Haughn, G., Saedler, H. and Schwarz-Sommer, Z. 1996. Non-cell-autonomous function of the Antirrhinum floral homeotic proteins DEFICIENS and GLOBOSA is exerted by their polar cell-to-cell trafficking. Development 122: 3433-3441.

Pickard, B.G. and Beachy, R.N. 1999. Intercellular connections are developmentally controlled to help move molecules through the plant. Cell 98: 5-8.

Postma-Haarsma, A.D., Verwoert, I.I.G.S., Stronk, O.P., Koster, J., Lamers, G.E.M., Hoge, J.H.C. and Meijer, A.H. 1999. Characterization of the KNOX class homeobox genes $O s k n 2$ and $O s k n 3$ identified in a collection of cDNA libraries covering the early stages of rice embryogenesis. Plant Mol. Biol. 39: 257-271.

Postma-Haarsma, A.D., Rueb, S., Scarpella, E., den Besten, W., Hoge, J.H.C. and Meijer, A.H. 2002. Developmental regulation and downstream effects of the knox class homeobox genes $O s k n 2$ and $O s k n 3$ from rice. Plant Mol. Biol. 48: 423-441.

Quaedvlieg, N.E.M., Schlaman, H.R.M., Admiraal, P.C., Wijting, S.E., Stougaard, J. and Spaink, H.P. 1998. Fusions between green fluorescent protein and beta-glucuronidase as sensitive and vital bifunctional reporters in plants. Plant Mol. Biol. 38: 861-873.

Reinhardt, D., Mandel, T. and Kuhlemeier, C. 2000. Auxin regulates the initiation and radial position of plant lateral organs. Plant Cell 12: 507-518.

Reinhardt, D., Pesce, E.-R., Stieger, P., Mandel, T., Baltensperger, K., Bennett, M., Traas, J., Friml, J. and Kuhlemeier, C. 2003. Regulation of phyllotaxis by polar auxin transport. Nature 426: 255-260.

Reiser, L., Sanchez-Baracaldo, P. and Hake, S. 2000. Knots in the family tree: evolutionary relationships and functions of knox homeobox genes. Plant Mol. Biol. 42: 151-166.

Sakamoto, T., Kamiya, N., Ueguchi-Tanaka, M., Iwahori, S. and Matsuoka, M. 2001. KNOX homeodomain protein directly suppresses the expression of a gibberellin biosynthetic gene in the tobacco shoot apical meristem. Genes Dev. 15: 581-590.

Sato, Y., Sentoku, N., Miura,Y., Hirochika, H., Kitano, H. and Matsuoka, M. 1999. Loss-of-function mutations in the rice homeobox gene $\mathrm{OSH} 15$ affect the architecture of internodes resulting in dwarf plants. EMBO J. 18: 992-1002.

Scanlon, M.J. 2003. The polar auxin transport inhibitor $N$-1naphthylphthalamic acid disrupts leaf initiation, KNOX 
protein regulation, and formation of leaf margins in maize. Plant Physiol. 133: 597-605.

Schoof, H., Lenhard, M., Haecker, A., Mayer, K.F.X., Jurgens, G. and Laux, T. 2000. The stem cell population of Arabidopsis shoot meristems is maintained by a regulatory loop between the CLAVATA and WUSCHEL genes. Cell 100: 635-644

Sentoku, N., Sato,Y., Kurata, N., Ito, Y., Kitano, H. and Matsuoka, M. 1999. Regional expression of the rice KNItype homeobox gene family during embryo, shoot, and flower development. Plant Cell 11: 1651-1664.

Serikawa, K.A., Martinez-Laborda, A. and Zambryski, P. 1996. Three knottedl-like homeobox genes in Arabidopsis. Plant Mol. Biol. 32: 673-683.
Sessions, A., Yanofsky, M.F., Weigel, D. 2000. Cell-cell signaling and movement by the floral transcription factors LEAFY and APETALA1. Science 289: 779-781.

Siemering, K.R., Golbik, R., Sever, R. and Haseloff, J. 1996. Mutations that suppress the thermosensitivity of green fluorescent protein. Curr. Biol. 6: 1653-1663.

Vandromme, M., Gauthier-Rouviere, C., Lamb, N. and Fernandez, A. 1996. Regulation of transcription factor localization: fine-tuning of gene expression. Trends Biochem. Sci. 21: 59-64.

Wu, X., Dinneny, J.R., Crawford, K.M., Rhee,Y., Citovsky,V., Zambryski, P.C. and Weigel, D. 2003. Modes of intercellular transcription factor movement in the Arabidopsis apex. Development 130: 3735-3745. 